\title{
Editorial: Ecological Non-equilibrium in the Anthropocene
}

\author{
Giovanni Rapacciuolo ${ }^{1 *}$, Andrew J. Rominger ${ }^{2,3}$, Naia Morueta-Holme ${ }^{4}$ and \\ Jessica L. Blois ${ }^{5}$ \\ ${ }^{1}$ Institute for Biodiversity Science and Sustainability, California Academy of Sciences, San Francisco, CA, United States, \\ ${ }^{2}$ Santa Fe Institute, Santa Fe, NM, United States, ${ }^{3}$ Department of Biology, University of New Mexico, Albuquerque, NM, \\ United States, ${ }^{4}$ Center for Macroecology, Evolution and Climate, GLOBE Institute, University of Copenhagen, Copenhagen, \\ Denmark, ${ }^{5}$ Life and Environmental Sciences, University of California, Merced, Merced, CA, United States
}

Keywords: ecological non-equilibrium, spatiotemporal scale, anthropocene, paleoecology, non-stationarity

\section{Editorial on the Research Topic}

\section{Ecological Non-equilibrium in the Anthropocene}

Much of our existing theory and methods in ecology assume that ecological systems are at equilibrium in space and time-that is, either environmental variation is assumed to be stationary or biological responses to fluctuating environments are assumed to be stable over large spatial and temporal scales. This assumption of equilibrium in ecology has led to common expectations that limited geographical areas or snapshots in time might provide sufficient knowledge to predict the larger-scale behavior of ecological systems. For instance, species distribution models (SDMs) are a commonly used tool to predict species' distributional shifts into new areas or new time periods from a spatiotemporally limited set of species' occurrences (Elith and Leathwick, 2009). Similarly, species-area relationships (SARs) have been widely used to extrapolate the rate of species extinction from habitat loss over areas much larger than those observed (Harte et al., 2009).

Accumulating evidence from both the paleo and modern records indicate that ecological systems rarely approach such perceived states of equilibrium (Svenning and Sandel, 2013; Rominger et al., 2016) and, consequently, that methods like SDMs and SARs often lead to misleading predictions (Smith, 2010; Yates et al., 2018). As we prepare to manage for change in the Anthropocene-an era characterized by the large-scale human modification of ecological systems-assumptions of ecological equilibrium hinder our ability to predict likely ecological responses over large spatial and temporal scales. As a result, incorporating non-equilibrium processes within ecological theories and methods has become crucial and timely, though it remains poorly recognized.

The collection of four papers in this Research Topic indicates that incorporating nonequilibrium in ecology will benefit from a three-pronged approach. Firstly, addressing nonequilibrium in ecology fundamentally requires understanding how empirical patterns in ecology vary as a function of spatial and temporal scale. Large quantities of data spanning continents and millennia from fossil deposits, museum specimens, ecological surveys, citizen science observations, remote sensing and next-generation sequencing are now openly available in online repositories. Gaüzère et al. and Sandel both take advantage of some of these big datasets to assess the degree of non-equilibrium in observed community responses to climate change. Gaüzère et al. describe the pattern of deviation between community-inferred climate values - the average niche temperature value of all species composing a community at a given time-and observed climate values over time and at multiple sites for plant communities during the Late Quaternary and bird communities during modern climate warming in North America. Doing so, they find that non-equilibrium responses to climate change, such as lagged responses and alternate states, 
are at least as common as equilibrium dynamics. Using the same bird data as Gaüzère et al., together with data on North American trees, Sandel compares the strength of the spatial and temporal relationships between the functional composition of species assemblages and mean annual temperature and annual precipitation. A key aspect of this approach is to vary the window of time over which climate predictors are calculated, from the previous one to ten years. Via this approach, Sandel finds that using 5- or 10-year averages of climate frequently increases the explanatory power of the climate trend compared to 1-year averages, particularly in birds. The analyses of Gaüzère et al. and Sandel show that this new wealth of large-scale ecological data, coupled with fundamental advances in the analytical ability to model such information and account for biases in each datum type (Rapacciuolo and Blois, 2019), now enable tackling questions about scale that had traditionally proved a challenge for ecologists. Sustained progress in this direction will require increasing integration among empirical approaches and data types-particularly between deep- and near-time approaches (Price and Schmitz, 2016; Pearse et al., 2018).

Secondly, in parallel with empirical approaches, nonequilibrium ecology will undoubtedly benefit from an increased focus on mechanistic, process-based models and simulations that explicitly test for the effects of different kinds of non-equilibrium dynamics on virtual ecological systems. In a perfect example of this, Chesson and Yang make a key advance to non-equilibrium ecology theory by providing a roadmap to modeling fluid populations-populations dispersing on a landscape undergoing non-stationary environmental change. Their new model extends the asymptotic environmentally determined trajectory (AEDT) theory (Chesson, 2017) to spatially structured populations. The AEDT is based on the assumption that, instead of approaching a fixed equilibrium value or a stationary distribution of fluctuations, a population process approaches a limiting trajectory, which depends on the past sequence of environmental states and the biology of the system. The model presented by Chesson and Yang moves us closer to understanding the behavior of populations whose parameters are both spatially and temporally varying functions. Going forward, some of the most compelling understanding of non-equilibrium processes in ecology is likely to emerge from the comparison of simulation outputs such as those of Chesson and Yang with empirical data across a range of model systems.

Thirdly, Newman reminds us that there is no need to reinvent the wheel because sub-disciplines of ecology, as well

\section{REFERENCES}

Chesson, P (2017). AEDT: a new concept for ecological dynamics in the everchanging world. PLoS Biol. 15:e2002634. doi: 10.1371/journal.pbio.2002634

Elith, J., and Leathwick, J. R. (2009). Species distribution models: ecological explanation and prediction across space and time. Annu. Rev. Ecol. Evol. Syst. 40, 677-697. doi: 10.1146/annurev.ecolsys.110308.120159

Harte, J., Smith, A. B., and Storch, D. (2009). Biodiversity scales from plots to biomes with a universal species-area curve. Ecol. Lett. 12, 789-797. doi: 10.1111/j.1461-0248.2009.01328.x as other scientific disciplines, have been grappling with issues of scale dependence and non-equilibrium for a long time. One discipline that is poised to provide invaluable insights into the responses of ecological communities to climate perturbations is disturbance ecology, because it directly studies dynamics and processes that both influence and respond to environmental heterogeneity over space and time. Based on this premise, Newman revisits some of the central themes of disturbance ecology in the context of the Anthropocene. A particularly useful concept in thinking about non-equilibrium is the idea that there is a useable reference period for the historical range of variability of disturbance regimes, such that we can distinguish somewhat normal patterns from "large, infrequent disturbances" that fall outside of two standard deviations for size, intensity, or other metrics of the historical disturbance regime. These events are likely to have disproportionate effects on assemblage composition in both the short and long term.

The new challenges the Anthropocene poses for ecological systems require us to pay increasing attention toward nonequilibrium processes in ecology. The collection of four papers in this Research Topic provide key contributions to the body of theory and methods necessary to incorporate non-equilibrium processes in ecology and a roadmap for advancing nonequilibrium ecology in the future.

\section{AUTHOR CONTRIBUTIONS}

GR wrote the first draft of this paper. All authors contributed to this paper by writing and editing portions of the submitted text.

\section{FUNDING}

GR was supported by United States National Science Foundation Dimensions of Biodiversity Program grant OCE-1241255. AR was supported by United States National Science Foundation grant DBI 1927319 and the Santa Fe Institute Omidyar Fellowship. NM-H was supported by an Individual Fellowship from Marie Skłodowska-Curie Actions (LUCCA 746334) and thanks the Danish National Research Foundation for support to the Center for Macroecology, Evolution and Climate (Grant DNRF96). JB was supported by a United States National Science Foundation Sedimentary Geo and Paleobiology Program grant EAR-1623852 awarded to JB. et al. (2018). Building up biogeography: Pattern to process. J. Biogeogr. 45, 1223-1230. doi: $10.1111 /$ jbi.13242

Price, S. A., and Schmitz, L. (2016). A promising future for integrative biodiversity research: an increased role of scale-dependency and functional biology. Philos. Trans. R. Soc. B. 371:169. doi: 10.1098/rstb.2015.0228

Rapacciuolo, G., and Blois, J. 1. (2019). Understanding ecological change across large spatial, temporal and taxonomic scales: integrating data and methods in light of theory. Ecography 42, 1247-1266. doi: 10.1111/ecog. 04616 
Rominger, A. J., Goodman, K. R., Lim, J. Y., Armstrong, E. E., Becking, L. E., Bennett, G. M., et al. (2016). Community assembly on isolated islands: macroecology meets evolution. Global Ecol. Biogeogr. 25, 769-780. doi: 10.1111 /geb.12341

Smith, A. B. (2010). Caution with curves: caveats for using the speciesarea relationship in conservation. Biol. Conserv. 143, 555-564. doi: 10.1016/j.biocon.2009.11.003

Svenning, J.-C., and Sandel, B. (2013). Disequilibrium vegetation dynamics under future climate change ${ }^{\dagger}$. Am. J. Bot. 100, 1266-1286. doi: 10.3732/ajb.1200469

Yates, K. L., Bouchet, P. J., Caley, M. J., Mengersen, K., Randin, C. F., Parnell, S., et al. (2018). Outstanding challenges in the transferability of ecological models. Trends Ecol. Evol. 33, 790-802. doi: 10.1016/j.tree.2018.08.001
Conflict of Interest: The authors declare that the research was conducted in the absence of any commercial or financial relationships that could be construed as a potential conflict of interest.

Copyright (c) 2019 Rapacciuolo, Rominger, Morueta-Holme and Blois. This is an open-access article distributed under the terms of the Creative Commons Attribution License (CC BY). The use, distribution or reproduction in other forums is permitted, provided the original author(s) and the copyright owner(s) are credited and that the original publication in this journal is cited, in accordance with accepted academic practice. No use, distribution or reproduction is permitted which does not comply with these terms. 